\title{
A Grounded Investigation of Game Immersion
}

\author{
Emily Brown and Paul Cairns \\ University College London Interaction Centre (UCLIC) \\ 31-32, Alfred Place, London WC1E 7DP, UK \\ ems_brown@hotmail.com,p.cairns@ucl.ac.uk \\ +44(0)2076795208
}

\begin{abstract}
The term immersion is widely used to describe games but it is not clear what immersion is or indeed if people are using the same word consistently. This paper describes work done to define immersion based on the experiences of gamers. Grounded Theory is used to construct a robust division of immersion into the three levels: engagement, engrossment and total immersion. This division alone suggests new lines for investigating immersion and transferring it into software domains other than games.
\end{abstract}

Author Keywords

Games, immersion, engrossment, engagement, flow, barrier

\section{ACM Classification Keywords}

K8.0 Personal Computing: General: Games; H5.1 Information interfaces and presentation: Multimedia Information Systems: evaluation.

\section{INTRODUCTION}

Immersion is a powerful experience of gaming, and has been mentioned by gamers [3], designers [12], and game researchers [10] alike as an important experience of interaction. However, when trying to understand immersion for transfer to another domain, it is very difficult to find out what exactly is meant by immersion and indeed even whether the different research on immersion is talking about the same concept.

This paper describes work done to develop a grounded theory [11] of immersion. More specifically, we interviewed gamers about their experiences of gaming and immersion whilst gaming and attempted to define qualities of immersion based on their experiences. The study suggests that gamers experience different levels of engagement with a game, the most engaged level being equated with immersion. However, total immersion can be difficult to achieve: there are barriers to immersion from both the human and the system perspectives.

The paper describes the method and results of our study together with a discussion of the implications of our

Copyright is held by the author/owner(s).

CHI 2004, April 24-29, 2004, Vienna, Austria.

ACM 1-58113-703-6/04/0004. findings. However, first, it is useful to consider previous work on immersion.

\section{EXISTING IDEAS ON IMMERSION}

The concept of immersion has been considered in many contexts but it is most commonly used, for software, when talking about virtual reality and games. In the game context, immersion is clearly considered to be very important. Game reviews mention immersion as related to the realism of the game world [7] or to the atmospheric sounds [1]. Immersion is also said to have depth [3]. The experience of immersion is often critical to game enjoyment and is made or destroyed by game characteristics. However, though immersion seems to be understood by the gaming community, it is not clear exactly what is meant by immersion and exactly what is causing it. There can be games with a realistic world and atmospheric sounds and yet immersion is not achieved [13].

Previous research has been scattered in several different areas. Virtual reality, game research and interface design consider the qualities of immersion and the game qualities that create the experience.

Often in such work, immersion is defined but it is not clear what is motivating the definition. For example, Douglas et al [5] discuss the structure of schemas in narrative and claim that these structural differences are what differentiate engagement from immersion and immersion from flow, that is, "the process of total involvement with life" [4]. This may well be an accurate portrayal of the authors' experiences but their concept of immersion may be quite different from those of gamers. Other works consider immersion as the essence of games [10] but once again immersion is not clearly defined. One thing Radford does do is relate immersion to the ability to enter the game through its controls. The invisibility of the tool is something discussed in more task-oriented software by Winograd and Flores [14] who refer to Heidegger's notion of a tool being "ready to hand." It is not clear from Radford's work to what extent to-handedness is an essential part of immersion or merely a precondition.

Virtual reality research has an interesting perspective on immersive experience. The concept of presence arises and is defined as the "extent to which a person's cognitive and perceptual systems are tricked into believing they are somewhere other than their physical location" [9]. Patrick 
et al (ibid) also propose that computer games and movies cannot provide this feeling of presence. Thus the question is: can gamers really never feel present? Or is there some sense in which, despite fact they are not physically surrounded by stimuli, they truly do feel present in a game?

The lack of clear meaning for immersion becomes acute when moving away from virtual reality and gaming and considering immersion in other types of software. Swing [12] attempts to add immersion to a collaborative tool. The result was a three dimensional world where each user had an avatar. It was uncertain whether this was more immersive than the previous tool because immersion was not defined and therefore no measures were available for comparing the experiences of the new and old software.

\section{METHOD}

Given the absence of a clear, transferable definition of immersion, our approach was to actually talk to gamers about what they meant by immersion. By working up what gamers say using Grounded Theory [11], the aim was to develop a robust concept of immersion that could be used or contrasted in other contexts.

We interviewed seven gamers, four men and three women approximately reflecting the known gender balance of gamers [6]. The participants were all English speakers, aged 18 and above, who regularly played computer games. To prime the interviewees, we first asked them to play their favourite game for up to thirty minutes. This was intended to make the gamer more aware of what it is that they enjoy about gaming and also what it is about a particular game that they enjoy.

Interviews were semi-structured. Questions were designed to prompt the interviewee about issues of immersion, for instance, asking them about a sense of presence and their experience of time whilst playing. For many of our participants, this was the first time they had talked about these experiences so particular care was taken to ask questions that did not put words into the interviewees' mouths.

Interviews were recorded and transcribed. Initially, the gamers had been videoed whilst playing to see if there were physical behaviours associated with gaming. As it turned out, there was so little physical action of any sort whilst gaming that this was not continued.

The interviews were analysed and coded using Grounded Theory. As this was a small study, the majority of the analysis was through open coding, identification of concepts and categories of concepts, and some axial coding, identification of relationships between categories.

\section{RESULTS}

As the intuitive use of the word suggests, immersion is indeed used to describe the degree of involvement with a game. This involvement moves along the path of time and is controlled by barriers. Some barriers can only be removed by human activity, such as concentration; others can only be opened by the game itself, such as the game construction. Each level of involvement is only possible if the barriers to the level are removed. Removing these barriers, however, only allows for the experience and does not guarantee it. Three levels of involvement were found: engagement; moving on to greater involvement in engrossment; and finally total immersion. In many ways, the barriers to immersion act to define and scope the level of involvement with the game. Each stage and the barriers to it will now be discussed with quotations from participants to illustrate our findings.

\section{Engagement}

The first stage of immersion is engagement. This is the lowest level of involvement with a game and must occur before any other level. To lower the barriers to enter this level, the gamer needs to invest time, effort, and attention. Accordingly, an initial barrier for engagement is access. This refers first to the gamers' preference, if they do not like a certain style of game they will not even try to engage with it.

"I don't tend to play sport games, I don't see the point really."

Secondly, access relates to game controls. The controls and feedback need to correspond in an appropriate manner so that the user can become expert, at least at the main controls.

"You just press anything just to try and kick, you don't really know what the controls are."

The second barrier to engagement is the investment the gamer puts into the game. The gamer must invest time into the game and this is relative to the game and the player. The gamers talk about how they "become focused" and that "if they played for ages" they would become more involved. Also as the gamer becomes more immersed they lose track of time, which can cause a feeling of guilt.

"You might look at your watch and think, you know, I've been playing computer games for hours and hours I could have been outside or talking to other people, so sometimes that's a bit strange."

The effort the gamers invest relates to the energy they put into learning how to play.

"When it comes to learning how to play some of these games it takes as much effort as a lot of productivity things."

Effort also relates to expected rewards. There is a feeling expressed that effort invested in a game should equal the rewards of success.

"[I have been playing this game] for fifteen years and I've never seen what's at the end of this poxy game...I want to know what's so special about getting to the end." 
Attention is best described as willingness to concentrate. It seems the demand for attention is greater in engrossing and totally immersive games compared to engaging games. Although this is initially a gamer investment at some point the game must provide something worthy of attending to.

The amount of time, effort and attention required from the gamer increases for more immersive experiences.

Once these two barriers of gamer investment and access are lowered the user begins to feel engaged. An engaged gamer is interested in the game and wants to keep playing. What this experience lacks is the emotional level of attachment that is seen in later levels of immersion.

\section{Engrossment}

From engagement the user may be able to become further involved with the game and become engrossed. The barrier to engrossment is game construction. This is when game features combine in such a way that the gamers' emotions are directly affected by the game.

"There are lots of games that are still loads of fun, but lack that semi-mystical quality of good construction."

Some game features mentioned by participants that form this quality were visuals, interesting tasks, and plot. Gamers could tell when a game was well constructed and could see when designers had put effort into construction. This added to their sense of respect for the game.

“They've spent a lot of time creating the little worlds. Making it look kind of sumptuous and realistic, I enjoy that."

At this level of immersion due to the time, effort and attention put in, there is a high level of emotional investment in the game. This investment makes people want to keep playing and can lead to people feeling "emotionally drained" when they stop playing. The game becomes the most important part of the gamers' attention and their emotions are directly affected by the game.

The gamer is now less aware of their surrounding and less self aware than previously.

"A Zen-like state where your hands just seem to know what to do, and your mind just carries on with the story."

"Everything else is irrelevant, you know it's there but it's irrelevant."

Some gamers purposefully construct a distraction free environment turning out lights and turning up the volume. Essentially gamers are involved with more than just the physical aspects of the game and have, in a sense, suspended their disbelief of the game world. This enables gamers to move towards total immersion.

\section{Total Immersion}

Total immersion is presence. Before discussing the barriers to the experience it is important to see what this experience is for gamers. Participants described being cut off from reality and detachment to such an extent that the game was all that mattered.

"When you stop thinking about the fact that you're playing a computer game and you're just in a computer"

"I suppose it's best described as a sense of being cut off from the world you actually inhabit."

"You just forget about the things around you and you're focused on what you're doing in the game"

"You feel like you're there"

At this point in the scale of immersion the game is the only thing that impacts the gamer's thoughts and feelings. The problem is that presence is only a fleeting experience.

"I don't think for the next couple of years we will feel like we're really there all the time apart from a few moments when someone is coming round a corner and shooting us and you get really scared. But it doesn't matter we feel that we are there enough."

The barriers to presence are empathy and atmosphere. Empathy is the growth of attachment and atmosphere the development of game construction. Empathy is distinct from attachment in that you feel attached to a main character or team but do not necessarily empathise with their situation. Gamers who did not feel total immersion talked of lack of empathy and the transfer of consciousness.

"I can't empathise with the dinosaur."

"I don't think I play the kind of games that would allow me to transfer my consciousness from one place to another completely."

Empathy was found to relate to several game features. All but one game mentioned as totally immersive was a first person perspective game. Also role-playing games were mentioned, where the gamers assumed a character.

Atmosphere is created from the same elements as game construction. The graphics, plot and sounds combine to create this feature. What makes atmosphere distinct from game construction is relevance. The game features must be relevant to the actions and location of the game characters. The reason this is important is because of the use of attention. If gamers need to attend to sound, as well as sight more effort is needed to be placed into the game. The more attention and effort invested, the more immersed a gamer can feel.

"The fact that you have to rely on your own senses."

Attention is an important part of immersion and in the case of total immersion the extent and location is important. The games seem to play with three elements of attention: visual, auditory and mental. The level of immersion felt by gamers seems to correlate to the number of attentional sources needed as well as the amount of each attentional type. 


\section{DISCUSSION AND FUTURE WORK}

In previous studies there were possibly divergent meanings of immersion and, hence, its causes. Now by looking at the gamers' experience of immersion we can begin to answer some important questions. First, are gamers talking about the same experience? This study found that there was a shared concept of immersion but this was not a static experience but described a scale of involvement with a game. Immersion was not a necessary feature for enjoyment and gamers choose games to play depending on mood. Is immersion something that people always enjoy? No one described an experience of immersion that they did not enjoy. However, this was moderated by guilt from a sense of wasting time on a game.

Several aspects of immersion discovered in this study correspond to the existing research on immersion. Radford's work [10] discussing entry into a game through controls, and Winograd's work on to-handedness correspond to access. However, here access is integral for any level of engagement with a game not just the more immersive levels. Norman claims that, in more task oriented software, users will put up with minor usability problems if the overall experience is pleasurable [8]. In contrast, engagement, and therefore enjoyment through immersion, is not possible if there are usability and control problems. Essentially there needs to be an invisibility of the controls for total immersion to take place. Usability flaws could hinder this. The threshold of usability flaws in games was not discussed and due to the fact people pay for these games, they possibly put much more effort into learning the game controls.

When looking at the features of immersion, there seem to be strong links with Czsentmihalyi's concept of flow [4], central to flow is attention. Any distraction from the task at hand causes the feeling of flow to be erased. Flow has some parallels with immersion in the fact that attention is needed, sense of time is altered, and sense of self is lost. Also, the use of skill and knowledge is the same in immersion as in flow. However the fleeting nature of total immersion seems to suggest that it is something distinct from flow in this context.

These findings on games and immersion offer many avenues for further research, such as manipulating interfaces for empathy and atmosphere. One participant referred to immersion as related to being distracted. This alone would be worth investigating in more depth. However, it is when considering immersion and therefore some form of enjoyment in other types of system that this study provides useful directions to follow. In particular, it is not clear when we would require a user to be fully immersed in a more traditional work-based task. However, there are contexts where this level of involvement may be advantageous. For example, in education it is clear that engagement, and possibly engrossment, are necessary parts of the learning process [2]. A better understanding of immersion and how to manipulate it could lead to better educational software for engaging students in learning.

Immersion is an intense experience that we have begun to clearly describe through its usage. Although this study has only scratched the surface we have laid the groundwork for the possibility to design for immersion.

\section{REFERENCES}

1. Benge D., Review: Sanatorium http://www.gamesdomain.co.uk/gdreview/zones/revie ws/pc/jun98/sanity.html

2. Bransford J.D., Brown A.L., Cocking R.R. Eds. How People Learn: Brain, Mind, Experience, and School. National Academy Press, 1999

3. Chown T., Review: Championship Manager 00/01 http://www.gamesdomain.co.uk/gdreview/zones/revie $\mathrm{ws} / \mathrm{pc} / \mathrm{nov} 00 / \mathrm{cm} 001 . \mathrm{html}$

4. Czsentmihalyi M. Flow: The Psychology of Optimal Experience. Harper Perennial, 1990

5. Douglas Y., Hargadon A. The Pleasure Principle: Immersion, Engagement and Flow. ACM 153-160,2000

6. ESA Pressroom, www.theesa.com/pressroom.html

7. Housten F., Review: Thief: The Dark Project. http://gamesdomain.com/gdreview/zones/pc/dec98/thie f.html

8. Norman D.A. Emotions and Design: Attractive Things Work Better. Interactions July and Aug, 36-42, 2002

9. Patrick E., Cosgrove D., Slavkovic A., Rode J.A. Verratti T., Chiselko G. Using a Large Projection Screen as an Alternative to Head-Mounted Displays for Virtual Environments. CHI Letters 2(1) 478-485, 2000

10. Radford A. Games and Learning about Form in Architecture. Automation in Construction, 9, 379-385, 2000

11. Strauss A., Corbin J. Basics of Qualitative, 2nd Ed. SAGE Publications. 1998.

12. Swing, E. Adding Immersion to Collaborative Tools. ACM Virtual Reality Modelling Symposium. 2000

13. Taylor J. Review of Circle of Blood http://www.gamesdomain.co.uk/gdreview/zones/revie ws/pc/jun97/cob.html

14. Winograd T., Flores F., Understanding Computers and Cognition. Norwood/NJ: Ablex. 1986 